\title{
Factors Associated With Severity of Motorcycle Injuries Among Young Adult Riders
}

Mau-Roung Lin, PhD Shu-Hui Chang, PhD Wenzheng Huang, PhD Hei-Fen Hwang, MS Lu Pai, PhD

From the Institute of Injury Prevention and Control, Taipei Medical University, Taipei, Taiwan, Republic of China (Lin); the Department of Public Health, School of Public Health, National Taiwan University, Taipei, Taiwan, Republic of China (Chang); the Department of Biostatistics, Harvard School of Public Health, Boston, MA (Huang); the Department of Nursing, National Taipei College of Nursing, Taipei, Taiwan, Republic of China (Hwang); and the Department of Public Health, National Defense Medical Center, Taipei, Taiwan, Republic of China (Pai).
Study objective: A cohort of 4,729 junior college students in Taiwan was studied to determine risk factors for increased severity of motorcycle injuries.

Methods: Crash characteristics were collected by using self-administered questionnaires soon after a student was involved in a motorcycle crash. The proportional odds model with generalized estimating equations, with correlated ordinal responses for collisions categorized into not injured, mildly injured, and severely injured categories, was used to determine the odds of injury severity.

Results: A total of 1,889 motorcycle crashes involving 1,284 persons occurred over a 20-month period from November 1994 to June 1996. There were 1,339 noninjuries, 474 mild injuries, and 76 severe injuries. The adjusted odds ratio (OR) of rural to urban roads having a greater level of injury severity was 1.64. Compared with noncollisions, collisions with a moving car (adjusted $\mathrm{OR}=1.76$ ), a parked car (adjusted OR 1.90), or another stationary object (adjusted $\mathrm{OR}=2.31$ ) increased the odds for a greater level of injury severity. Riders using Sanyang (adjusted $\mathrm{OR}=1.63$ ) and Yamaha (adjusted $\mathrm{OR}=1.39$ ) motorcycles had greater odds of being involved in a crash with a greater level of injury compared with those riding Kymco motorcycles. Darkness (adjusted OR=1.65) and greater speeds (adjusted $\mathrm{OR}=1.63$ to 4.69 ) also increased the odds of greater injury severity.

Conclusion: At the time of motorcycle crashes, factors such as being on rural roads, collisions with a heavier object, some motorcycle makes, darkness, and greater speeds increased the severity of motorcycle injuries among these young adult riders. [Ann Emerg Med. 2003;41:783-791.] 


\section{INTRODUCTION}

Motorcycles in Taiwan are a major means of transportation and a common source of injury. According to police reports, $43 \%$ of the 2,717 deaths from traffic injuries in Taiwan in 1992 were among motorcycle riders, and of these motorcyclist deaths, $31 \%$ were young riders aged 16 to 25 years. ${ }^{1}$ Emergency department records have shown that more than $66 \%$ of motorcycle injuries occur to riders aged younger than 20 years. ${ }^{2-4}$ Thus, identifying features and behaviors that might reduce injuries, especially among young riders, would be of value.

There are several inadequacies in previous studies related to severity of motorcycle injuries. First, police and hospital records traditionally used in motorcycleinjury studies are incomplete in that they usually overrepresent severely injured riders. ${ }^{5,6}$ Only $53 \%$ to $91 \%$ of hospital admissions and $37 \%$ to $38 \%$ of ED visits caused by motorcycle injuries were reported by the police. ${ }^{7-12}$ Motorcycle injuries caused by some crashes, such as onscene deaths, mild injuries, and noninjuries, are often not included in hospital records. Hence, a representative sample of motorcycle crashes, particularly for determination of risk or protective factors for motorcycle injuries, is required to obtain unbiased results, as well as to validate those results from police and hospital records. Second, potential factors associated with severity of motorcycle injuries have only rarely been comprehensively measured in previous studies, and thus, independent effects of risk or protective factors on severity of injury might be inaccurately estimated.

Finally, it is common for recurrent injuries to occur to a rider over time, but injury has often been treated as being independent; that is, only the first event for multiple events is counted. ${ }^{13,14}$ Traditional statistical models using correlated data might result in inefficient estimates of regression parameters and inconsistent estimates of precision. ${ }^{15}$

Therefore, because of the high occurrence of motorcycle injuries in young adults, we believed that it was appropriate to conduct a cohort study of a representative sample of motorcycle crashes in this age group, with the goal of estimating the magnitude of risk factors for injury severity in this group.

\section{MATERIALS AND METHODS}

Junior college students from 2 residential areas, Taipei (an urbanized area in Taiwan with a population density of 10,001 persons per square kilometer) and Hualien (a rural area with a population density of 76 persons per square kilometer), were selected for this study. Two junior colleges from each area were randomly selected from a total of 8 junior colleges in Taipei and 3 in Hualien. Because one of the selected colleges in Taipei declined to participate, only 3 junior colleges were included in the study. Students attending junior colleges in Taiwan complete a series of 5 grades before graduation. Students in the first and second years, who have fewer opportunities to ride a motorcycle because they are not yet of legal age (18 years), were not included in this study. The study population initially consisted of 4,721 students (2,224 from Taipei and 2,497 from Hualien) who were enrolled at the 3 participating schools at the beginning of the study. One initial and 3 follow-up assessments were conducted at the beginning of the study and at approximate 6-month intervals during a 20-month study period from November 1994 to June 1996. A total of 4,729 students completed at least 1 of the 4 assessments over the study period (some students entered or withdrew from the 3 schools). This research was reviewed by the institutional review board at the National Defense Medical Center in Taiwan, and informed consent was obtained from all participants and the authorities of the 3 schools.

Several methods were used to identify motorcycle crashes occurring to students. First, crash information was mainly collected through class representatives elected by students. Students reported motorcycle crashes occurring in the past week to their representatives at their weekly class meeting, and then student representatives asked them to complete a motorcycle crash form containing structured questions regarding the crash characteristics. An economic incentive, NT $\$ 500$ (approximately US $\$ 20$ at the study time) for 
each representative per month, was provided to the representatives during the study period to facilitate representative participation in reporting motorcycle crashes. Furthermore, researchers contacted the representatives by telephone every 2 weeks to remind them to report any motorcycle crashes that had occurred in the previous 2 weeks. Second, the 3 follow-up assessments for all students were also used to supplement the aforementioned student representative reports. At each followup assessment visit, we checked on whether there were students who had been involved in a crash they had not reported to representatives and asked them to complete the motorcycle crash form. Finally, it is compulsory for schools in Taiwan to record severe injuries, such as deaths and injuries requiring hospitalization, even though the records depend on the victims or their close classmates being willing to report the crash to the school. School records were checked monthly to examine whether some severe motorcycle crashes were missed. As a result, 2 fatal injuries were not reported by the previous reporting systems, and therefore, school and hospital records and interviews with families were used to obtain the corresponding crash information.

The motorcycle crash questionnaire collected information on the student's behavior immediately before the crash, on the type of motorcycle involved in the crash, and on environmental factors at the time of the crash. The characteristics in the questionnaire were classified into 3 general categories: human factors, vehicular factors, and environmental factors. Human factors included age at the time of the crash, riding experience, sex, riding position (operator or passenger), motorcycle licensure and ownership, helmet use, alcohol consumption, and riding speed. Vehicular factors included engine volume, model year, and make of motorcycle involved in the crash. Environmental factors included crash location (urban or rural roads), collision object, day of the week, light conditions, weather, and surface, width, profile, and roadway alignment (straight versus curved) where the crash occurred.

Motorcycle crashes were defined as having occurred when the rider or riders fell down onto the road, either in a single- or multiple-vehicle collision. Motorcycle crashes were further categorized into 3 levels of injury severity: noninjury, mild injury, and severe injury. An injury was defined as mild when a motorcycle rider sought medical care at least once but was not hospitalized as a result of the crash. An injury was defined as severe when riders were hospitalized or died from the crash. Crashes that did not lead riders to seek any medical service were categorized as noninjuries.

The distribution of the time of day of the 1,889 motorcycle crashes occurring in the study period was plotted. Categoric variable distributions among the 3 levels of injury severity were compared by using Pearson $\chi^{2}$ tests. For ordinal variables, Mantel-Haenszel $\chi^{2}$ tests for trends were also computed.

The proportional odds model ${ }^{16}$ was used to investigate the relationships of the 3 levels of motorcycle injuries with the multiple potential risk factors. We assumed that the integers $1, \ldots, \mathrm{k}$, indicate the k-ordered response categories, and $\pi_{j}, j=1, \ldots, \mathrm{k}$, are the multinomial probabilities of being in each category. The model proposes the following:

$$
\operatorname{logit}\left(\gamma_{j}\right)=\ln \left(\gamma_{j} /\left[1-\gamma_{j}\right]\right)=\theta_{j}-\beta^{\mathrm{T}} x, j=1, \ldots, \mathrm{k}-1,
$$
where $\gamma_{j}=\pi_{1}+\ldots+\pi_{j}$ are cumulative probabilities of being in one of the first $j$ categories; $\ln ($.$) is the natural logarith-$ mic function; $\theta_{j}$ and $\beta$ are unknown parameters; and $x$ is a vector of explanatory variables. ${ }^{17}$ This model assumes that the effect of one exposure variable is the same across cumulative logits. Therefore, a single effect of the exposure, indicated by the log odds ratio $(\beta)$ or odds ratio $\left(e^{\beta}\right)$, on the cumulative logits can be estimated. In this study, because 407 of 1,284 riders who were involved in at least one crash experienced multiple crashes during the follow-up period, the correlation of multiple crashes involving the same individual was adjusted by using generalized estimating equations in the proportional odds model. ${ }^{18,19}$ In the initial multivariate analysis of the proportional odds model, variables with a $P$ value of less than .25 in the univariate analysis were included. ${ }^{20} \mathrm{In}$ addition, the goodness-of-fit ${ }^{21}$ and the assumption of proportional odds ${ }^{22}$ specifically for generalized estimating equation models were also assessed. Statistical Analysis Software (version 6.12, SAS Institute, Inc., Cary, NC) was used for all statistical analyses. 
To assess the reliability of the participants' original responses to the motorcycle crash form, we selected 150 forms to ask students the same questions as appeared on the form by telephone. Of these, 140 were completed within 1 month after the crash had been reported. $\kappa$ Values for the crash characteristics ranged from 0.55 to 0.98 , and the average $\kappa$ value of these characteristics was 0.74 . This average $\kappa$ value indicates substantial strength of agreement between the original and retest responses on the crash questionnaire. ${ }^{23}$

\section{RESULTS}

During the 20-month study period, a total of 1,889 motorcycle crashes involving 1,284 study participants occurred. Of the 1,284 participants experiencing at least one motorcycle crash during the 20-month study period, 877 had one crash, 280 had 2 crashes, and 127 had 3 or more crashes. About $80 \%$ of the total crashes were reported by class representatives, $20 \%$ were from crash victims at the 3 follow-up assessment visits, and 2 fatal crashes were obtained from school records.

The time-of-day distribution for the occurrence of motorcycle crashes, as shown in the Figure, exhibited 2 peaks at $8 \mathrm{Am}$ and $5 \mathrm{PM}$, corresponding to the times of going to school and getting out of school, respectively.
Conversely, the lowest numbers of motorcycle crashes occurred between 4 AM and 5 AM.

Of the 1,889 motorcycle crashes, 1,339 were categorized into the noninjury category, 474 into the mild injury category, and 76 into the severe injury category. Table 1 presents the distributions of human factors in the 3 severity levels of motorcycle injuries. At greater levels of injury severity, the proportion of riders aged 17 and 20 years was somewhat greater, and that of riders aged 18 and 19 years was smaller. With increasing injury severity, a greater proportion of motorcycles was owned by the victim or his or her classmate, and conversely, a smaller proportion was owned by his or her family. The proportion of greater riding speeds, alcohol drinkers, or helmet nonusers increased with greater levels of injury severity.

As shown in Table 2, no significant differences in the 3 levels of injury severity were detected among various motorcycle engine volumes or among various model years. However, with increasing injury severity, the proportion of riders using Sanyang motorcycles increased, and conversely, the proportion using Kymco models decreased.

Table 3 presents the distributions of environmental factors for the 3 levels of injury severity. The proportion of motorcycle crashes occurring on rural roads, at night, or in unstable weather increased with greater levels of

\section{Figure.}

Time-of-day distribution for the occurrence of 1,889 motorcycle crashes involving 1,284 persons over a 20-month follow-up period.

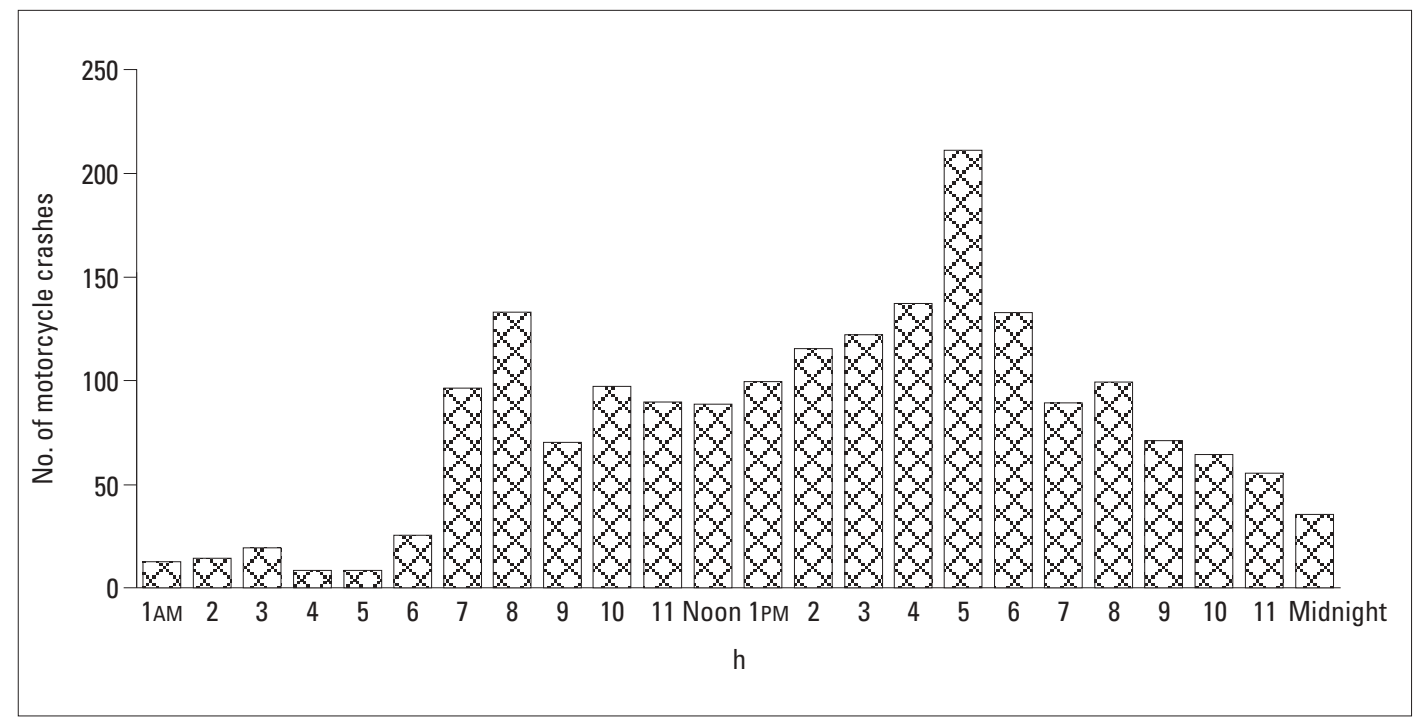


injury severity. In addition, the proportion of collisions involving a moving car or a stationary object, such as a post, tree, or guardrail on the roadside, also increased at greater levels of injury severity.

Table 4 shows the results of the proportional odds model with generalized estimating equation analysis. The 2 intercepts (ie, $\theta_{1}$ and $\theta_{2}$ ) in the model are not displayed because they are nuisance parameters and do not

Table 1.

Distributions of human factors for 3 levels of injury severity among 1,889 motorcycle crashes.

\begin{tabular}{|c|c|c|c|c|}
\hline Characteristic & $\begin{array}{c}\text { All } \\
\text { Crashes, } \\
\text { No. (\%) }\end{array}$ & $\begin{array}{c}\text { Non- } \\
\text { injury, } \\
\text { No. }(\%)\end{array}$ & $\begin{array}{l}\text { Mild } \\
\text { Injury, } \\
\text { No. (\%) }\end{array}$ & $\begin{array}{l}\text { Severe } \\
\text { Injury, } \\
\text { No. (\%) }\end{array}$ \\
\hline \multicolumn{5}{|l|}{ Age at crash, y } \\
\hline 17 & $53(2.8)$ & $30(2.2)$ & $19(4.0)$ & $4(5.3)$ \\
\hline 18 & $590(31.2)$ & $419(31.3)$ & $150(31.7)$ & $21(27.6)$ \\
\hline 19 & $815(43.1)$ & $595(44.4)$ & $190(40.1)$ & $30(39.5)$ \\
\hline 20 & $333(17.6)$ & $228(17.0)$ & $85(17.9)$ & $20(26.3)$ \\
\hline$\geq 21$ & 98 (5.2) & $67(5.0)$ & $30(8.3)$ & $1(1.3)$ \\
\hline \multicolumn{5}{|c|}{ Riding experience, $\mathrm{y}^{*}$} \\
\hline$<1$ & $150(15.8)$ & $107(16.0)$ & $39(16.4)$ & $4(9.5)$ \\
\hline 1 & $310(32.6)$ & $225(33.6)$ & $71(29.8)$ & $14(33.3)$ \\
\hline 2 & $172(18.1)$ & $125(18.7)$ & $38(16.0)$ & $9(21.4)$ \\
\hline 3 & $123(13.0)$ & $86(12.8)$ & $29(12.2)$ & $8(19.1)$ \\
\hline$\geq 4$ & $195(20.5)$ & $127(19.0)$ & $61(25.6)$ & 75 (16.7) \\
\hline \multicolumn{5}{|l|}{ Sex } \\
\hline Male & $768(40.7)$ & 552 (41.2) & $180(38.0)$ & $36(47.4)$ \\
\hline Female & $1,121(59.3)$ & 787 (58.8) & $294(62.0)$ & $40(52.6)$ \\
\hline \multicolumn{5}{|l|}{ Riding position } \\
\hline Operator & $1,510(79.9)$ & $1,084(81.0)$ & $354(76.8)$ & $62(81.6)$ \\
\hline \multirow{2}{*}{\multicolumn{5}{|c|}{ Motorcycle licensure }} \\
\hline & & & & \\
\hline No & $553(29.3)$ & $378(28.2)$ & $151(31.9)$ & $24(31.6)$ \\
\hline Yes & $1,336(70.7)$ & $961(71.8)$ & $323(68.1)$ & $52(68.4)$ \\
\hline \multicolumn{5}{|c|}{ Motorcycle ownership } \\
\hline Victim & $1,127(59.7)$ & 793 (59.2) & $285(60.1)$ & $49(64.5)$ \\
\hline Family & $325(17.2)$ & $250(18.7)$ & 72 (15.2) & $3(4.0)$ \\
\hline Classmate & $342(18.1)$ & 231 (17.3) & $91(19.2)$ & $20(26.3)$ \\
\hline Other & $95(5.0)$ & $65(4.9)$ & $26(5.5)$ & $4(5.3)$ \\
\hline \multicolumn{5}{|l|}{ Helmet use } \\
\hline No & $1,269(67.2)$ & $883(65.9)$ & $328(69.2)$ & $58(76.3)$ \\
\hline Yes & $620(32.8)$ & $456(34.1)$ & $146(30.8)$ & $18(23.7)$ \\
\hline \multicolumn{5}{|c|}{ Alcohol consumption } \\
\hline No & $1,830(96.9)$ & $1,304(97.4)$ & $455(96.0)$ & 71 (93.4) \\
\hline Yes & $59(3.1)$ & $35(2.6)$ & $19(4.0)$ & $5(6.6)$ \\
\hline \multicolumn{5}{|c|}{ Riding speed, km/h } \\
\hline$<21$ & $229(12.1)$ & $186(13.9)$ & $39(8.2)$ & $4(5.3)$ \\
\hline $21-40$ & $788(41.7)$ & $584(43.6)$ & $182(38.4)$ & $22(29.0)$ \\
\hline $41-60$ & 611 (32.4) & 418 (31.2) & 165 (34.8) & $28(36.8)$ \\
\hline $61-80$ & $209(11.1)$ & $121(9.0)$ & $71(15.0)$ & $17(22.4)$ \\
\hline$\geq 81$ & $52(2.8)$ & $30(2.2)$ & $17(3.6)$ & $5(6.6)$ \\
\hline
\end{tabular}

affect inferences from the results. After controlling for the effects of other risk factors, the adjusted odds ratio (OR) for a greater level of injury severity from motorcycle crashes on rural roads compared with those on urban roads was 1.64 , with a $95 \%$ confidence interval (CI) of 1.30 to 2.06. After adjusting for other factors, motorcycle crashes involving a moving car (adjusted OR $=1.76 ; 95 \%$ CI 1.34 to 2.30), a parked car (adjusted $\mathrm{OR}=1.90 ; 95 \%$ CI 1.24 to 2.92 ), or another stationary object (adjusted OR=2.31;95\% CI 1.49 to 3.60) were found to more likely produce a greater level of injury severity to riders compared with crashes without a collision. Riders using Sanyang (adjusted OR $=1.63 ; 95 \%$ CI 1.20 to 2.19) or Yamaha (adjusted OR $=1.39 ; 95 \%$ CI 1.05 to 1.85 ) models remained at significantly increased odds of a greater level of injury severity in a motorcycle crash compared with those using Kymco models. Motorcycle crashes occurring in the dark were more likely to have a greater level of injury severity than those occurring in daylight (adjusted OR $=1.65 ; 95 \%$ CI 1.14 to 2.40). After adjustment, a greater riding speed was still significantly associated with a greater level of injury severity, and a positive monotonic relationship

Table 2.

Distributions of vehicular factors for 3 levels of injury severity among 1,889 motorcycle crashes.

\begin{tabular}{|c|c|c|c|c|}
\hline Characteristic & $\begin{array}{c}\text { All } \\
\text { Crashes, } \\
\text { No. }(\%)\end{array}$ & $\begin{array}{l}\text { Non- } \\
\text { injury, } \\
\text { No. }(\%)\end{array}$ & $\begin{array}{c}\text { Mild } \\
\text { Injury, } \\
\text { No. (\%) }\end{array}$ & $\begin{array}{l}\text { Severe } \\
\text { Injury, } \\
\text { No. (\%) }\end{array}$ \\
\hline \multicolumn{5}{|c|}{ Engine volume, cc } \\
\hline 50 & 807 (43.2) & $564(42.3)$ & $212(45.1)$ & $31(40.8)$ \\
\hline $70-110$ & $188(10.6)$ & $134(10.1)$ & $50(10.6)$ & $4(5.3)$ \\
\hline 125 & 726 (38.9) & $528(39.9)$ & $164(34.9)$ & $34(44.7)$ \\
\hline$>125$ & $147(7.9)$ & $96(7.3)$ & $44(9.4)$ & $7(9.2)$ \\
\hline \multicolumn{5}{|l|}{ Model year } \\
\hline$\leq 1991$ & $235(17.0)$ & $168(16.9)$ & $57(16.6)$ & $10(21.7)$ \\
\hline 1992 & $154(11.1)$ & $112(11.2)$ & 38 (11.1) & $4(8.7)$ \\
\hline 1993 & $279(20.1)$ & $196(19.7)$ & $75(21.9)$ & 8 (17.4) \\
\hline 1994 & $428(30.9)$ & $302(30.3)$ & $109(31.8)$ & $17(37.0)$ \\
\hline$\geq 1995$ & $290(20.9)$ & $219(22.0)$ & $64(18.7)$ & 7 (15.2) \\
\hline \multicolumn{5}{|l|}{ Make } \\
\hline Sanyang & $537(28.8)$ & $363(27.5)$ & $143(30.6)$ & $31(41.9)$ \\
\hline Kymco & $490(26.3)$ & $371(28.1)$ & $105(22.5)$ & 14 (18.9) \\
\hline Yamaha & $753(40.4)$ & $527(40.0)$ & $199(42.6)$ & 27 (36.5) \\
\hline Other & $83(4.5)$ & $61(4.6)$ & $20(4.3)$ & $2(2.7)$ \\
\hline
\end{tabular}


between riding speed and injury severity was also found. The adjusted ORs for the 4 greater speed groups relative to the lowest speed group of less than $21 \mathrm{~km} / \mathrm{h}$ in sequence were 1.63 (95\% CI 1.13 to 2.35 ), 2.16 (95\%

Table 3.

Distributions of environmental factors for 3 levels of severity among 1,889 motorcycle crashes.

\begin{tabular}{|c|c|c|c|c|}
\hline Characteristic & $\begin{array}{c}\text { All } \\
\text { Crashes, } \\
\text { No. }(\%)\end{array}$ & $\begin{array}{c}\text { Non- } \\
\text { injury, } \\
\text { No. }(\%)\end{array}$ & $\begin{array}{c}\text { Mild } \\
\text { Injury, } \\
\text { No. }(\%)\end{array}$ & $\begin{array}{l}\text { Severe } \\
\text { Injury, } \\
\text { No. (\%) }\end{array}$ \\
\hline \multicolumn{5}{|l|}{ Crash location } \\
\hline Urban road & $1,253(66.3)$ & $933(69.7)$ & $280(59.1)$ & $40(52.6)$ \\
\hline Rural road & 636 (33.7) & $406(30.3)$ & $194(40.9)$ & $36(47.4)$ \\
\hline \multicolumn{5}{|l|}{ Collision object } \\
\hline No object hit & $572(30.3)$ & $417(31.1)$ & $139(29.3)$ & $16(21.1)$ \\
\hline Moving car & $543(28.8)$ & $360(26.9)$ & $153(32.3)$ & $30(39.5)$ \\
\hline Moving motorcycle & $476(25.2)$ & $368(27.5)$ & $96(20.3)$ & $12(15.8)$ \\
\hline Other moving object & $86(4.6)$ & $61(4.6)$ & $22(4.6)$ & $3(4.0)$ \\
\hline Parked car & $86(4.6)$ & $54(4.0)$ & $28(5.9)$ & $4(5.3)$ \\
\hline Parked motorcycle & $34(1.8)$ & $28(2.1)$ & $5(1.1)$ & $1(1.3)$ \\
\hline Other stationary object & $92(4.9)$ & $51(3.8)$ & $31(6.5)$ & $10(13.2)$ \\
\hline \multicolumn{5}{|l|}{ Days of the week } \\
\hline Sunday & $278(14.7)$ & $192(14.3)$ & $73(15.4)$ & $13(17.1)$ \\
\hline Monday & $274(14.5)$ & $197(14.7)$ & $68(14.4)$ & $9(11.8)$ \\
\hline Tuesday & 249 (13.2) & $178(13.3)$ & $67(14.1)$ & $4(5.3)$ \\
\hline Wednesday & $254(13.5)$ & $179(13.4)$ & 64 (13.5) & $11(14.5)$ \\
\hline Thursday & $260(13.8)$ & $183(13.7)$ & 65 (13.7) & $12(15.8)$ \\
\hline Friday & $256(13.6)$ & $187(14.0)$ & $59(12.5)$ & $10(13.2)$ \\
\hline Saturday & $318(16.8)$ & $223(16.7)$ & $78(16.5)$ & $17(22.4)$ \\
\hline \multicolumn{5}{|l|}{ Light conditions } \\
\hline Daylight & $296(15.7)$ & $206(15.4)$ & 78 (16.5) & $12(15.8)$ \\
\hline Twilight & $1,042(55.2)$ & 762 (56.9) & $250(52.7)$ & $30(39.5)$ \\
\hline Dark but lighted & $407(21.6)$ & $289(21.6)$ & $97(20.5)$ & $21(27.6)$ \\
\hline Dark & $144(7.6)$ & $82(6.1)$ & 49 (10.3) & $13(17.1)$ \\
\hline \multicolumn{5}{|l|}{ Weather } \\
\hline Sunny & $979(51.8)$ & $708(52.9)$ & $235(49.6)$ & $36(47.4)$ \\
\hline Cloudy & $479(25.4)$ & $338(25.2)$ & $120(25.3)$ & $21(27.6)$ \\
\hline Rainy & 366 (19.4) & $251(18.8)$ & $103(21.7)$ & $12(15.8)$ \\
\hline Unstable & $65(3.4)$ & $42(3.1)$ & $16(3.4)$ & 7 (9.2) \\
\hline \multicolumn{5}{|l|}{ Roadway surface } \\
\hline Blacktop & $1,458(77.2)$ & $1,030(76.9)$ & $366(77.2)$ & $62(81.6)$ \\
\hline Concrete & $157(8.3)$ & $114(8.5)$ & $36(7.6)$ & $7(9.2)$ \\
\hline Gravel & $176(9.3)$ & $117(8.7)$ & 54 (11.4) & $5(6.6)$ \\
\hline Other & $98(5.2)$ & $78(5.8)$ & $18(3.8)$ & $2(2.6)$ \\
\hline \multicolumn{5}{|l|}{ Roadway width } \\
\hline One way/1 lane & $307(16.3)$ & $226(16.9)$ & $72(15.2)$ & $9(11.8)$ \\
\hline One way/ $\geq 2$ lanes & $204(10.8)$ & $139(10.4)$ & $59(12.5)$ & $6(7.9)$ \\
\hline Two way/2 lanes & $675(35.7)$ & $470(35.1)$ & $172(36.3)$ & $33(43.4)$ \\
\hline Two way/ $\geq 4$ lanes & $703(37.2)$ & $504(37.6)$ & $171(36.1)$ & $28(36.8)$ \\
\hline \multicolumn{5}{|l|}{ Roadway profile } \\
\hline Level & $1,747(92.5)$ & 1,239 (92.5) & $435(91.8)$ & $73(96.1)$ \\
\hline Uphill & $60(3.2)$ & $45(3.4)$ & $14(3.0)$ & $1(1.3)$ \\
\hline Downhill & $82(4.3)$ & $55(4.1)$ & $25(5.3)$ & $2(2.6)$ \\
\hline \multicolumn{5}{|l|}{ Roadway alignment } \\
\hline Straight & $1,717(90.9)$ & $1,216(90.8)$ & $436(92.0)$ & $65(85.5)$ \\
\hline Curved & $172(9.1)$ & $123(9.2)$ & $38(8.0)$ & $11(14.5)$ \\
\hline
\end{tabular}

CI 1.46 to 3.20 ), 4.05 (95\% CI 2.61 to 6.27 ), and 4.69 (95\% CI 2.45 to 8.96), respectively. After adjustment, riders who did not have a valid motorcycle license were marginally associated with a greater level of injury severity (adjusted OR=1.26;95\% CI 1.00 to 1.59 ). The goodness-of-fit statistic for this model was 9.86, with 9 degrees of freedom and a $P$ value of .296, and the robust score statistic for testing proportionality was 15.29 , with a $P$ value equal to .704 .

\section{DISCUSSION}

We collected a population-based sample of motorcycle crashes by following up more than 4,700 junior college students over a 20-month period to examine the risk factors for 3 levels of severity of motorcycle injuries. In

Table 4.

Result of proportional odds model with generalized estimating equation analysis: Adjusted ORs with 95\% CIs for increased severity levels of motorcycle injuries.

\begin{tabular}{|c|c|c|c|}
\hline Characteristic & OR & $95 \% \mathrm{Cl}$ & $P$ Value \\
\hline \multicolumn{4}{|l|}{ Crash location } \\
\hline Urban road & 1.00 & - & \\
\hline Rural road & 1.64 & $1.30-2.06$ & 0 \\
\hline \multicolumn{4}{|l|}{ Collision object } \\
\hline No object hit & 1.00 & - & \\
\hline Moving car & 1.73 & $1.31-2.26$ & 0 \\
\hline Moving motorcycle & 0.92 & $0.68-1.23$ & .568 \\
\hline Other moving object & 1.14 & $0.69-1.88$ & .605 \\
\hline Parked car & 1.89 & $1.23-2.90$ & .004 \\
\hline Parked motorcycle & 0.79 & $0.34-1.80$ & .568 \\
\hline Other stationary object & 2.34 & $1.50-3.65$ & 0 \\
\hline \multicolumn{4}{|l|}{ Motorcycle make } \\
\hline Kymco & 1.00 & - & \\
\hline Sanyang & 1.64 & $1.21-2.22$ & .001 \\
\hline Yamaha & 1.42 & $1.07-1.88$ & .015 \\
\hline Other & 1.35 & $0.79-2.32$ & .277 \\
\hline \multicolumn{4}{|l|}{ Light conditions } \\
\hline Daylight & 1.00 & - & \\
\hline Twilight & 1.22 & $0.93-1.60$ & .142 \\
\hline Dark but lighted & 1.13 & $0.88-1.46$ & .345 \\
\hline Dark & 1.66 & $1.14-2.40$ & .008 \\
\hline \multicolumn{4}{|l|}{ Riding speed, km/h } \\
\hline$<21$ & 1.00 & - & \\
\hline $21-40$ & 1.63 & $1.13-2.36$ & .009 \\
\hline $41-60$ & 2.14 & $1.45-3.15$ & 0 \\
\hline $61-80$ & 3.95 & $2.56-6.10$ & 0 \\
\hline$\geq 81$ & 4.59 & $2.41-8.75$ & 0 \\
\hline
\end{tabular}


the proportional odds model, generalized estimating equations were applied to adjust the correlation between recurrent motorcycle crashes for a single individual. Although the study population was limited to young adult riders, we believe the identified risk factors, particularly for vehicular and environmental factors, can be generalized to other riding populations to prevent injuries at the time of a crash.

Although taking many human and environmental factors into account in the study, motorcycle make was still independently associated with severity levels of motorcycle injuries. Although some studies have reported that mechanical defects in tires and brakes contribute to traffic crashes, ${ }^{24,25}$ our data are insufficient to provide further information on why Sanyang and Yamaha motorcycle riders had a greater risk of a significantly greater level of injury severity in a crash compared with those riding Kymco models. More research is required to validate whether this finding results from an inherent mechanical aspect of a particular make, from being confounded by other unmeasured humanenvironmental factors, or from a type I error. This result is worthy of further study because Sanyang and Yamaha motorcycles are commonly used in many countries in which the population-attributable risk of motorcycle injuries with these makes could be high if the result is valid.

In this study, alcohol consumption and helmet use were not independently associated with risk of a greater level of injury severity. Because only 3.1\% of the total crashes in the study population were reported to involve alcohol consumption, the background incidence of motorcycle injuries in the population (or in Taiwan) is high, or both, the power to detect the effect of alcohol consumption on the severity levels of motorcycle injuries was weakened. Alternatively, alcohol consumption might not play an important role in the occurrence of less severe injuries, even though it is often reported to cause fatal injuries. ${ }^{26,27}$ The ability to detect the protective effect of helmets on all kinds of motorcycle injuries was reduced because head and facial injuries comprised only $16 \%$ of the 550 injuries in this study. The result implies that more attention should be fo- cused on prevention of injuries other than those to the head of motorcycle riders that result in poor prognosis. However, the protective effect of helmets specifically on head and facial injuries is reported elsewhere. ${ }^{28}$

There are at least 4 limitations to this study. First, the total number of reported motorcycle crashes might not have been complete. Almost all of the crashes reported by the victims did not involve an injury. In addition, these crashes tended to be noncollisions or to occur among students without a valid motorcycle license. If this were true for unreported crashes, then the effects of collision object and motorcycle licensure were underestimated in this study.

Second, the motorcycle crashes and their characteristics were self-reported, and no available sources can be used to validate this information. Although motor vehicle crashes reported from adolescents and young adults are often valid and reliable $e^{29-31}$ and the average $\kappa$ value for test-retest questions in the study was 0.74 , behavioral factors, such as alcohol consumption, helmet use, and high speeds, unexpected by social norms were possibly underreported, and therefore, their effects would be underestimated.

Third, the actual levels of injury severity were vulnerable to misclassification because the classification of injury severity in this study might have been subject to differences between individuals and between hospitals. In other words, in this study, the definition of mild injuries (ie, seeking medical care at least once) might be intertwined with the availability of care and factors that affect care-seeking behavior; furthermore, the definition of severe injury (ie, hospitalization caused by a motorcycle crash) might also depend on standards for admission. This problem exists in other measures for injury severity as well. For example, lost days of usual activities are applied to define an injury by the National Health Survey in the United States. As another example, "evident, but not incapacitating, or complaint of injury" and "killed or incapacitating," terms often used by police to judge the existence of minor-moderate and severe-fatal injury, ${ }^{32}$ are more subjective. Our study did not adopt the commonly used Abbreviated Injury Score,${ }^{33}$ the Injury Severity Score, ${ }^{34}$ or other instru- 
ments that measure injury severity for hospitalized patients because they are insensitive to less severe injuries ${ }^{13,14}$ and thus might not be appropriate for our study, which involved a number of minor injuries.

Finally, there might be model overfitting because the 27 degrees of freedom used by the candidate independent variables in the initial multivariate analysis is large relative to the 76 cases in the smallest outcome level, and models with fewer than 10 outcome events per independent variable are generally thought to have questionable accuracy. ${ }^{35-37}$ To quantify overfitting, we computed the shrinkage coefficient, ${ }^{38}$ which was 0.88 , indicating that about $12 \%$ of the model is noise, and thus the overfitting was mild. ${ }^{39}$ In addition, a bootstrap resampling method ${ }^{40,41}$ was applied to validate the reliability of the results obtained from the model. The verified proportionality assumption should help to alleviate the overfitting problem by allowing data in other categories to be used in estimating the rate of events in the group with severe injuries. ${ }^{42}$

In summary, because a substantial proportion of motorcycle crashes among young adult riders cannot be easily avoided, an increased emphasis on reducing injury severity at the time of the crash is needed. Factors such as being on rural roads, collisions with a heavier object, some motorcycle makes, darkness, and greater speeds might increase the severity of motorcycle injuries among young adult riders, indicating the importance of improving road environments (eg, reducing open drains in rural roads and providing adequate lighting for roads), driving behaviors (eg, enforcement of riding within speed limits and avoiding riding close to cars), and vehicle designs for reducing injury severity in motorcycle crashes.

Author contributions: $\mathrm{M}-\mathrm{RL}, \mathrm{H}-\mathrm{FH}$, and LP designed and supervised the conduct of data collection for this study. M-RL, S-HC, and WH managed the data, provided statistical consultation, and performed the data analysis. M-RL drafted the manuscript, and S-HC and WH contributed to the manuscript revisions. M-RL takes responsibility for the paper as a whole.

Received for publication March 30, 2001. Revisions received March 20, 2002; September 3, 2002; September 27, 2002; November 13, 2002; and January 13, 2003. Accepted for publication January 26, 2003.
Supported by funding from the National Science Council, Executive Yuan, Taiwan, Republic of China (grant NSC 88-2314-B-039-036).

Address for reprints: Mau-Roung Lin, PhD, Institute of Injury Prevention and Control, Taipei Medical University, $250 \mathrm{Wu}$-Hsing Street, Taipei 110, Taiwan, ROC; 886-2-27226109, fax 886-2-27390387; E-mailmrlin@tmu.edu.tw.

\section{REFERENCES}

1. Ministry of Communication and Transportation. Annual Report of Transportation and Communication in 1992. Taipei, Taiwan: Executive Yuan, Republic of China; 1993.

2. Chao SH, Tan KY. Motorcycle injuries - an epidemiologic study of emergency room patients in a large hospital in Taipei City. $J$ Natl Public Health Assoc (ROC). 1984;4:26-32.

3. Ding SL, Wang JD, Chen KT. Estimate of case fatality rate and incidence rate of traffic injury in Taiwan-analysis of 4,329 victims at a medical center. J Formosan Med Assoc. 1993;92:S76-S81.

4. Wu SI, Yang GY, Chou P, et al. Analysis of traffic injuries in Taiwan in relation to alcohol use and economic loss. Injury. 1992;22:357-361.

5. Rutledge R, Stutts J. The association of helmet use with the outcome of motorcycle crash injury when controlling for crash/injury severity. Accid Anal Prev. 1993;25:347-353.

6. Aptel I, Salmi LR, Masson F, et al. Road accidents: discrepancies between police and hospital data in French Island. Accid Anal Prev. 1999;31:101-108.

7. Cercarelli LR, Rosman DL, Ryan GA. Comparison of accident and emergency with police road injury data. J Trauma. 1996;40:805-809.

8. Rosman DL, Knuiman MWA. Comparison of hospital and police road injury data. Accid Anal Prev. 1994;26:215-222

9. Harris $S$. The real number of road traffic accident casualties in the Netherlands: a year-long survey. Accid Anal Prev. 1990;22:371-378.

10. Maas MW, Harris S. Police recording of road accident in-patients-investigation into the completeness, representativity and reliability of police records of hospitalized traffic victims. Accid Anal Prev. 1984;16:167-184.

11. Kraus JF, Riggins RS, Franti CE. Some epidemiologic features of motorcycle collision injuries. I. Introduction, methods and factors associated with incidence. Am J Epidemiol. 1975;102:74-98.

12. Bull JP, Roberts BJ. Road accident statistics - a comparison of police and hospital information. Accid Anal Prev. 1973;5:45-53.

13. Cummings $P$, Koepsell, TD, Mueller BA. Methodological challenges in injury epidemiology and injury prevention research. Annu Rev Public Health. 1995;16:381-400.

14. Veazie MA, Landen DD, Bender TR, et al. Epidemiologic research on the etiology of injuries at work. Annu Rev Public Health. 1994;15:203-211.

15. Zeger SL, Liang KY. An overview of methods for the analysis of longitudinal data. Stat Med. 1992;11:1825-1839.

16. McCullagh P. Regression models for ordinal data. J Roy Stat Soc B. 1980;42:109-142. 17. McCullagh P, Nelder JA. Generalized Linear Models. London, United Kingdom: Chapman Hall; 1983.

18. Liang KY, Zeger SL. Longitudinal data analysis using generalized linear models. Biometrika. 1986;73:13-22.

19. Lipsitz SR, Kim K, Zhao L. Analysis of repeated categorical data using generalized estimating equations. Stat Med. 1994;13:1149-1163.

20. Mickey RM, Greenland S. The impact of confounder selection criteria on effect estimation. Am J Epidemiol. 1989;129:125-137.

21. Horton NJ, Bebchuk JD, Jones CL, et al. Goodness-of-fit for GEE: an example with mental health service utilization. Stat Med. 1999;18:213-222.

22. Stiger TR, Barnhart HX, Williamson AM. Testing proportionality in the proportional odds model fitted with GEE. Stat Med. 1999;18:1419-1433. 
MOTORCYCLE INJURIES AMONG YOUNG ADULT RIDERS

Lin et al

23. Landis JR, Koch GG. The measurement of observer agreement for categorical data. Biometrics. 1977;33:159-174.

24. Schoor 0 , Niekerk JL, Grobbelaar B. Mechanical failures as a contributing cause to motor vehicle accidents-South Africa. Accid Anal Prev. 2001;33:713-721.

25. Treat JR. A Study of Precrash Factors Involved in Traffic Accidents. Ann Arbor, MI: Highway Safety Research Institute; 1980. Publication No. HSRI 10/11, 6/1.

26. National Highway Traffic Safety Administration. Traffic Safety Facts 1996. Washington, DC: US Department of Transportation; 1996

27. Baker SP, O'Nell B, Ginsburg MJ, et al. The Injury Fact Book. 2nd ed. New York, NY: Oxford University Press; 1992.

28. Lin MR, Hwang HF, Kuo NW. Crash severity, injury patterns, and helmet use in adolescent motorcycle riders. J Trauma. 2001;50:24-30.

29. Begg DJ, Langley JD, Williams SM. Validity of self reported crashes and injuries in a longitudinal study of young adults. Injury Prev. 1999;5:142-144.

30. Jelalian E, Alday S, Spirito A, et al. Adolescent motor vehicle crashes: the relationship between behavioral factors and self-reported injury. J Adolesc Health. 2000;27:84-93.

31. Burger MC, Lichtenstein MJ, Hays JT, et al. Association of self-reported injury and alcohol consumption in medical outpatients. J Gen Intern Med. 1990;5:486-489.

32. National Highway Traffic Safety Administration. General Estimates System 1989A Review of Information on Police-Reported Traffic Crashes in the United States. Washington, DC: US Department of Transportation; 1989.

33. Association for the Advancement of Automotive Medicine. The Abbreviated Injury Scale, 1990 Revision. Des Plaines, IL: Association for the Advancement of Automotive Medicine; 1990.

34. Baker SP, O'Nell B, Haddon W, et al. The Injury Severity Score: a method for describing patients with multiple injuries and evaluating emergency care. J Trauma. 1974;14:187-196.

35. Harrell FE, Lee KL, Califf RM, et al. Regression modeling strategies for improved prognostic prediction. Stat Med. 1984;3:143-152.

36. Concato J, Peduzzi P, Holford TR, et al. Importance of events per independent variables in proportional harzards analysis. I. Background, goals, and general strategy. J Clin Epidemiol. 1995;48:1495-1501.

37. Peduzzi P, Concato J, Feinstein AR, et al. Importance of events per independent variables in proportional hazards analysis. II. Accuracy and precision of regression estimates. J Clin Epidemiol. 1995;48:1503-1510.

38. van Houwelingen JC, le Cessie S. Predictive value of statistical models. Stat Med. 1990;9:1303-1325.

39. Harrell FE, Lee KL, Mark DB. Multivariable prognostic models: issues in developing models, evaluating assumptions and adequacy, and measuring and reducing errors. Stat Med. 1996;15:361-387.

40. Efron B. The Jackknife, the Bootstrap, and Other Resampling Plans. Philadelphia, PA: SIAM; 1982.

41. Booth JG, Sarkar S. Monte Carlo approximation of bootstrap variances. Am Stat. 1998;52:354-357.

42. Whitehead J. Sample size calculations for ordered categorical data. Stat Med. 1993;12:2257-2271. 